\title{
Establishment of anti-HBcAg Monoclonal Antibodies for Sandwich ELISA Application by Iliac Method Utilizing Incomplete Adjuvant
}

\author{
Endah Puji Septisetyani ${ }^{\text {a, }}$, Nina Herlina ${ }^{\text {a }}$, Arizah Kusumawati ${ }^{\text {, }}$ Pekik Wiji Prasetyaningrum ${ }^{\text {a }}$, \\ Anika Prastyowati ${ }^{\mathrm{a}}$, Adi Santoso ${ }^{\mathrm{a}}$, Apon Zaenal Mustopa ${ }^{\mathrm{a}}$ \\ ${ }^{a}$ Research Center for Biotechnology, National Research and Innovation Agency (BRIN), \\ Jl. Raya Bogor KM 46, Cibinong, Bogor, West Java, 16911, Indonesia \\ Corresponding author: *enda041@brin.go.id
}

\begin{abstract}
The prevalence of hepatitis B virus (HBV) infection in Indonesia was moderate in 2013. This makes an appropriate action has to be taken immediately. In an attempt to evaluate our candidate HBV vaccine efficacy, we generated monoclonal antibodies specific to HBcAg for sandwich ELISA application for research purposes. Monoclonal antibodies are generally developed using hybridoma technology by isolating B cells from spleen or lymph nodes followed by fusion with myeloma cells. This study generated hybridoma by modifying the iliac lymph node method and used incomplete Freund's adjuvant to emulsify the antigen. For this purpose, an elevenweek-old BALB/c mouse was immunized with a single shot recombinant HBcAg water in oil emulsion intramuscularly at the mouse tail base. After one month, besides enlargement of the medial iliac lymph nodes, we also found that the sub-iliac lymph nodes were enlarged. In two different fusion attempts, the single B cells were then isolated from each lymph node and fused with SP2/0-Ag14 mouse myeloma cells. Hybridoma cells derived from both lymph nodes were screened by ELISA coated with HBcAg peptide. As a result, we obtained two positive wells of hybridoma polyclones from each medial iliac and sub-iliac-derived B lymphocyte. After monoclonalization, we obtained candidate anti-HBcAg monoclonal antibodies as either capture or detection antibodies. Furthermore, we successfully retrieved hybridoma clones 9.3, 9.4, and 9.5, which could produce monoclonal antibodies for sandwich ELISA application.
\end{abstract}

Keywords - HBcAg; iliac method; incomplete adjuvant; monoclonal antibodies; sandwich ELISA.

Manuscript received 29 Aug. 2020; revised 12 Dec. 2020; accepted 15 Mar. 2021. Date of publication 31 Dec. 2021. IJASEIT is licensed under a Creative Commons Attribution-Share Alike 4.0 International License.

(C) () ()

\section{INTRODUCTION}

Hepatitis B is a disease generated by hepatitis B virus (HBV) infection. The HBVs target hepatocytes to replicate, which may induce liver inflammation or enlargement [1]. In 2007, the prevalence of HBV infection in Indonesia was high in endemicity based on national surveillance of hepatitis B surface antigen (HBsAg), anti-hepatitis B core antigen (anti$\mathrm{HBcAg}$ ), and anti-HBsAg [2]. In 2013, the prevalence of HBV decreased to $7.1 \%$ of the Indonesian population, changing the prevalence status from high to moderate [3]. HBV is transmitted by percutaneous and mucosal exposure to infective blood or body fluids. Major modes of $\mathrm{HBV}$ transmission include sexual or close household contact with an infected person, the transmission of the perinatal mother to child, injection of drug use, and nosocomial infection [4].

As a disease that causes global health problems, hepatitis $\mathrm{B}$ can cause complications that can endanger lives [5]. Longterm hepatitis B infection may promote more serious effects such as cirrhosis, liver failure, or hepatocellular carcinoma [1], [6]-[8]. In an attempt to reduce new cases of HBV, the Indonesian government supports hepatitis B immunization which may reduce the risks of vertical transmission [9]. Evaluation of anti-HBsAg titers in younger subjects (younger than 19-year-old) was increasing among the Indonesian subjects tested, indicating successful vaccination attempts. However, decreasing titers of anti-HBcAg among those subjects may indicate the need for vaccination using $\mathrm{HBcAg}$ based vaccine [10].

HBsAg, which is located in the outer part of the virus, both in the mature virus and DNA-negative virus particle, serves as a common target for detecting HBV infection, determining viral load, and vaccine development [11]-[13]. It represents active viral infection [14]. However, HBsAg-negative serological samples determined by immunoassays could generate false-negative results due to possible mutations at the $\mathrm{S}$ gene or its promoter region [15]-[17]. In addition, those HBsAg negative samples could be detected as positive by 
determining anti-HBcAg or HBV DNA. Hence, antibody to $\mathrm{HBcAg}$ is important to diagnose occult $\mathrm{HBV}$ infection where HBsAg is undetectable.

Moreover, titers of anti-HBcAg are also beneficial for assessing natural history, reactivation, predicting the therapeutic responses, and predicting the need for HBV vaccination [18], [19]. Thedja and his colleagues [15] reported that forty-three percent of HBsAg-negative samples out of 309 samples were detected positive for anti-HBcAg while 8.1 percent of HBsAg-negative samples showed HBV DNA signal by polymerase chain reaction (PCR). Furthermore, even though the detection and quantification of HBV DNA by PCR are indeed more sensitive methods, immunoassays are easier and faster to be carried out. HBV DNA quantification is the most accurate method; however, the application requires special expertise and high costs. Consequently, the HBV immunoassay is the most common, easy-to-use, and inexpensive detection method [14].

Hepatitis B core-related antigens (HBcrAgs) consist of hepatitis $\mathrm{B}$ core antigen ( $\mathrm{HBcAg}), \mathrm{HBeAg}$, and a pre-core protein p22cr [11]. Compared to HBsAg, HBcrAgs are located in the inner part of HBV. HBcAg is a 183-polypeptide chain which transcribed and translated from the core gene to build the nucleocapsid. It also plays multiple roles from viral replication, viral persistence, viral-host interaction to hepatocarcinogenesis [11], [20], [21]. On the other hand, $\mathrm{HBeAg}$, which shares a 149-amino acid identity with $\mathrm{HBcAg}$, is a soluble core protein secreted from host cells and circulated in the host body. These HBcrAgs can induce host adaptive immune response by recruiting cytotoxic $\mathrm{T}$ lymphocytes and become the target for vaccine development in combination with $\mathrm{HBsAg}$ to provoke better immune response [22], [23]. More recently, HBcrAgs based immunoassay provides a more sensitive assay than $\mathrm{HBsAg}$ based immunoassay for HBV detection [24], especially in patients with spontaneous HBsAg loss and the patients with nucleoside analogs (NAs) therapy [11]. In addition, HBcrAg level is related with HBV covalently closed circular DNA (cccDNA) level observed by PCR [25] which is beneficial for the prediction of treatment outcome and disease progression [26].

In this study, we generated monoclonal antibodies specific to $\mathrm{HBcAg}$ to establish sandwich ELISA for research purposes. We modified the iliac method developed by Sado and his colleagues [27] by utilizing incomplete Freund's adjuvant to emulsify $\mathrm{HBcAg}$ peptide. Interestingly, in addition to medial iliac lymph nodes, we also found enlargement of sub-iliac lymph nodes, generating positive clones secreting anti-HBcAg antibodies.

\section{Material And Method}

All in vivo experiments complement the ethical committee regulation (Animal Care and Use Committee of Research and Community Services Institution IPB University No. 149/KEH/SKE/VIII/2019).

\section{A. Mouse Immunization}

Healthy male BALB/c mice aged 8-week with an average of $20 \mathrm{~g}$ body weight were obtained from PT. BLST, Bogor, Indonesia. Food and water were given to the mice ad libitum. Fitzgerald obtained a 183 aa of $19 \mathrm{kDa}$ recombinant $\mathrm{HBcAg}$ peptide expressed in yeast for mouse immunization. Seventy microlitres of $2 \mu \mathrm{g} / \mu \mathrm{l} \mathrm{HBcAg}$ was emulsified in $300 \mu \mathrm{l}$ incomplete Freund's adjuvant (ICFA) (Sigma). About $46 \mu \mathrm{g}$ of peptide in a total of $100 \mu \mathrm{l}$ emulsion was injected intramuscularly at the base tail of an 11-week-old BALB/c mouse. One month after single-shot immunization, the mouse was sacrificed to isolate both the enlarged medial iliac and sub-iliac lymph nodes. Single B lymphocytes suspension was obtained by passing the lymph nodes through a $70 \mu \mathrm{m}$ cell strainer (Corning).

\section{B. Cell Fusion}

SP 2/0-Ag14 mouse myeloma cells were used for cell fusion. The cells were obtained from the European Collection of Authenticated Cell Culture (ECACC 85072401). The cells were maintained in RPMI medium (Sigma) supplemented with $10 \%$ FBS (Sigma) and antibiotics $100 \mathrm{IU} / \mathrm{ml}$ penicillin$100 \mu \mathrm{g} / \mathrm{ml}$ streptomycin in humidified 5\% CO2 incubator at $37^{\circ} \mathrm{C}$. Confluent cells were harvested using $0.25 \%$ trypsin/EDTA (Sigma). The B cells were fused with SP 2/0Ag14 cells for hybridoma generation by using polyethylene glycol (Roche). Next, the fused cells were resuspended in a selection medium containing 10\% FBS (Sigma), 10\% BMcondimned H1 (Roche), as well as hypoxanthine aminopterin and thymidine (HAT) (Sigma) and seeded onto 96-well plate. Non-fusion cells will not survive under an HAT-containing medium, leaving the successfully generated hybridoma to grow.

\section{Screening of Hybridoma and Monoclonalization}

Two weeks after hybridoma selection in HAT medium, the hybridoma conditioned medium was used for ELISA to screen the clones which produce antibodies against $\mathrm{HBcAg}$. For this purpose, $50 \mathrm{ng} / \mathrm{well}$ of recombinant $\mathrm{HBcAg}$ peptide in sodium carbonate buffer $\mathrm{pH} 9.6$ was used to coat ELISA plate and incubated overnight at $4{ }^{\circ} \mathrm{C}$. The next day, the plates were washed with PBS-T and incubated with 5\% skim milk/PBS-T for one hour. Following the next washing, $20 \mu \mathrm{l}$ of each conditioned medium was added to each well containing $80 \mu \mathrm{l}$ PBS-T and incubated at $4^{\circ} \mathrm{C}$. After 24 hours, the plates were washed and incubated with HRP-conjugated anti-mouse IgG $\gamma$-chain secondary antibody $(1: 5,000)$ for one hour. Then, the antibody solution was removed and washed with PBS-T, followed by the addition of $80 \mu \mathrm{l}$ ABTS chromogenic substrate (Invitrogen). The absorbance of the developed color reaction was measured at OD $405 \mathrm{~nm}$. The positive clones were then harvested and gradually transferred onto 12 and 6 well-plates. HAT containing medium was replaced with HT containing medium for cell recovery. To obtain monoclones, the candidate hybridoma cells were seeded back onto 96-well plate after a limiting dilution of 1 cell/well. Two weeks later, ELISA again examined the clones to retrieve monoclones that secrete anti-HBcAg antibodies. The successful clones were then propagated to collect more conditioned medium and make the frozen stocks.

\section{Screening of Monoclonal Antibodies by Sandwich ELISA of Conditioned Medium}

After being transferred onto $35 \mathrm{~mm}$ dishes, confluent hybridoma cells were washed with PBS and incubated in serum-free hybridoma medium (Sigma) supplemented with 
10\% BM-condimned H1. Three days later, the conditioned medium was collected, and the cells were replenished with a new medium and continue incubated for three days to collect another conditioned medium. The collected serum-free conditioned medium was used for sandwich ELISA to retrieve candidate monoclonal antibodies which are applicable for either capture or detection antibodies. Conditioned medium from $5 \# 21$ derived monoclones were used to coat ELISA plate and represent capture antibody. After blocking with skim milk in PBS-T, HBcAg peptide was added as antigen. Then, a conditioned medium from 9\#4 derived monoclones was added to represent detection antibodies. As for the control wells, the second conditioned medium was not added to the wells. To visualize the immuno-reaction, HRP conjugated anti-mouse secondary antibody was added, followed by the addition of ABTS substrate to generate a turquoise color. The signal observed by the microplate reader was analyzed by subtracting the OD405 of wells containing both conditioned medium of 5\#21 and 9\#4 derived monoclones with OD405 of each control well without a conditioned medium of $9 \# 4$ derived monoclones.

\section{E. Purification of Monoclonal Antibodies by Protein $A / G$ Agarose}

Hybridoma conditioned medium was incubated with protein $\mathrm{A} / \mathrm{G}$ agarose (Abcam) at $4{ }^{\circ} \mathrm{C}$ at the rotating platform. One hour later, the suspension was transferred into an empty polypropylene column (Biorad), and the beads were settled down by gravity. After collecting the flow-through, the beads were washed with PBS. Next, the bound antibodies were eluted with $100 \mathrm{mM}$ glycine $\mathrm{pH} 2.7$ and collected in microtubes containing one-tenth of the expected final volume of $1 \mathrm{M}$ Tris $\mathrm{pH} 9$ to neutralize the acidic $\mathrm{pH}$. To observe the purified antibodies, flow-through, washed and elution fractions were subjected to SDS-PAGE and Coomassie brilliant blue staining. Elution fractions that contained the most concentrated antibodies were then dialyzed with PBS. Finally, the antibody concentration was determined by a nano-spectrophotometer.

\section{F. Preparation of HRP-conjugated Monoclonal Antibody}

Purified monoclonal antibodies in PBS were conjugated to HRP by using an HRP-lightning link kit (Abcam). Briefly, one kit of $10 \mu \mathrm{g}$ HRP-lightning link was mixed with 9.3, 9.4, and 9.5 monoclonal antibodies at a final volume of $20 \mu \mathrm{l}$. Modifier was added two microliters per $20 \mu \mathrm{l}$ volume before the addition of HRP. After overnight incubation at room temperature in the dark, a quencher was added two microliters per $20 \mu \mathrm{l}$ reaction. The HRP-conjugated $\mathrm{mAbs}$ were used for sandwich ELISA 30 minutes later.

\section{G. Sandwich ELISA application using HRP-conjugated monoclonal antibodies}

Each well of the ELISA plate was coated with $50 \mathrm{ng}$ of each purified 9.3, 9.4, or 9.5 monoclonal antibodies, conditioned medium of hybridoma clone 5.2, $25 \mathrm{ng}$ mouse $\operatorname{IgG}$ isotype control, and commercial HBcAg $(1: 2,000)$. After coating and blocking with $3 \%$ skim milk, the $\mathrm{HBcAg}$ peptide was added $36 \mathrm{ng}$ or four ng per well. Then, HRP-linked 9.3, 9.4, or 9.5 monoclonal antibodies $(1: 300)$ were added, followed by the addition of ABTS substrate for color development.

\section{RESULTS AND DISCUSSION}

HBV infection can be detected either by DNA isolation and amplification by PCR or immunoassays [28]. PCR is more sensitive, but it is more difficult and expensive [28]-[30]. On the other hand, immunoassay such as ELISA is easier and faster to detect a higher number of samples [31], [32]. Most ELISA developed for HBV infection utilized HBsAg-based detection. However, mutation of HBsAg may lead to a false negative analysis [15], [33]. Thus, anti-HBcAg immunoassay is also combined with HBsAg detection for more comprehensive analyses [34]. More recently, a sensitive immunoassay based on HBcrAgs was developed utilizing monoclonal antibodies against $\mathrm{HBcAg}$ and $\mathrm{HBeAg}$ [35], [36]. The assay is more sensitive than HBsAg-based immunoassay, while the results are associated with HBV DNA levels in serological samples [35]. Moreover, $\mathrm{HBcAg}$ is one of HBcrAgs, which also developed as candidate HBV vaccines, especially in combination with HBsAg [22]. Therefore, we generated our monoclonal antibodies against $\mathrm{HBcAg}$ to develop homemade sandwich ELISA for research purposes.
A.

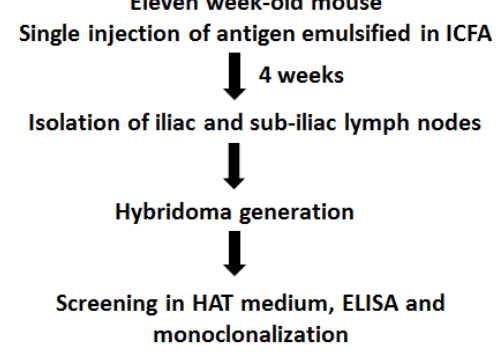

B.

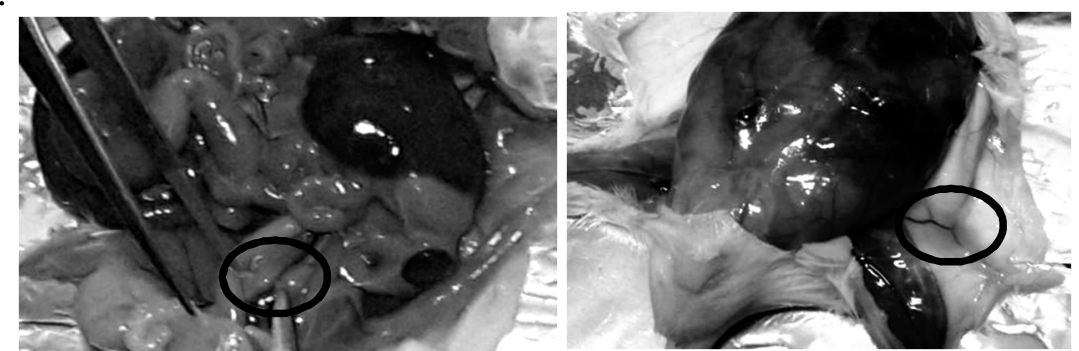

Fig. 1 Mouse immunization and isolation of lymph nodes. A. Schematic representation of hybridoma generation. B. Enlargement of medial iliac (left panel) and sub-iliac (right panel) lymph nodes of immunized mouse after single shot of HBcAg peptide emulsified in incomplete Freund's adjuvant (ICFA). Open circle represents the location of lymph node. 


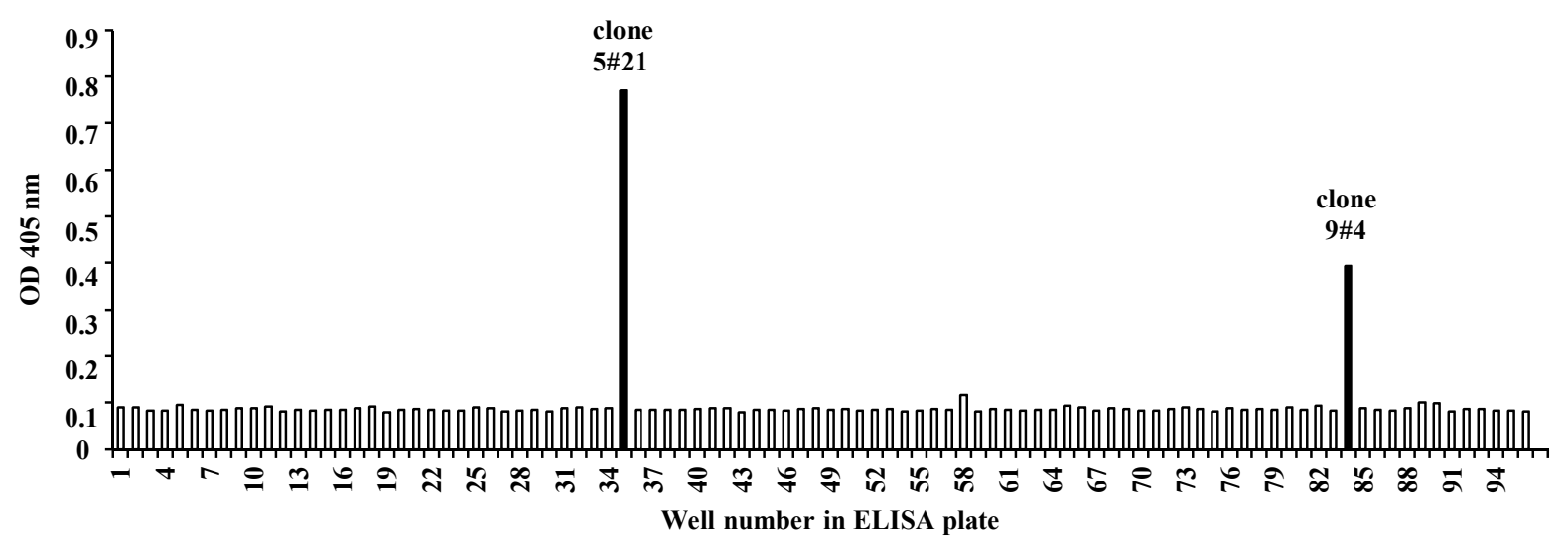

Fig. 2 Screening of candidate hybridomas by using ELISA plate coated with HBcAg retrieved two candidate polyclonal hybridomas $5 \# 21$ and $9 \# 4$.
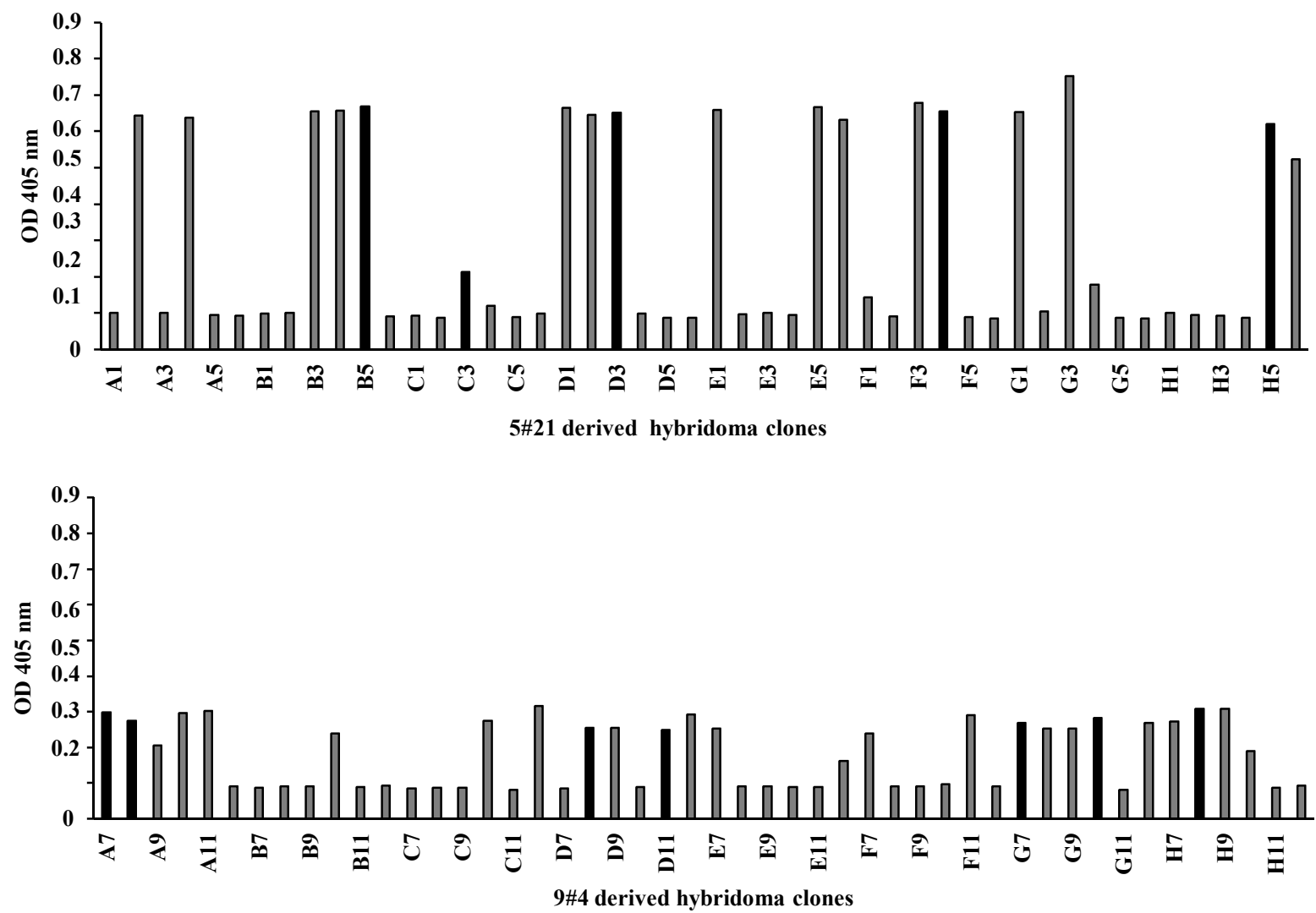

Fig. 3 ELISA screening of 5\#21 and 9\#4derived monoclonal hybridomas. The black bars indicated candidate monoclonal hybridomas, which were retrieved for further experiment.

\section{A. Hybridoma Generation and Screening}

Hybridoma techniques are commonly used to generate monoclonal antibodies (mAbs), the essential tools for research and diagnostic. There are a variety of procedures that can be applied to immunize the animals and isolate spleen or lymph nodes to prepare hybridoma. In this study, we modified the procedure established by Sado and colleagues [27], [37]. We utilized a single injection of $\mathrm{HBcAg}$ peptide emulsified in ICFA applied intramuscularly at the base tail of 11-week-old $\mathrm{BALB} / \mathrm{c}$ mouse to enlarge iliac lymph nodes (Fig. 1.A.). Unlike complete Freund's adjuvant (CFA), which is generally used for first immunization, ICFA, which is usually used as booster adjuvant, does not contain $M$. tuberculosis cell extract to induce Toll-Like Receptor (TRL) response. However, CFA induces additional severe lesions at the injection sites. On the other hand, ICFA still maintains its function as a water-in-oil emulsion adjuvant to release the antigen slowly from the injection spot and prolong antigen exposure to the host immune system [38] while mediating the activation of dendritic cells, which sequentially generate follicular T helper cells and promote antibody production by follicular B cells [39]. Our protocol found enlargement of medial iliac lymph nodes and sub-iliac lymph nodes (Fig. 1.B.). One month after a single immunization, we isolated both enlarged medial iliac and sub-iliac lymph nodes located close to the injection sites to retrieve antibody-secreting $\mathrm{B}$ cells. The intramuscular injection has been widely applied for vaccination to generate 
antibody responses of local lymph nodes [40]. After about two weeks, we selected 96 growing clones under a HATcontaining medium to screen hybridoma conditioned medium by ELISA using an HBcAg coated plate. As a result, we retrieved two candidates polyclonal hybridoma clones, clone $5 \# 21$, which derived from medial iliac B cell, and clone 9\#4, which derived from sub-iliac B cell. Furthermore, conditioned medium from clone $5 \# 21$ demonstrated a higher signal for $\mathrm{HBcAg}$ detection than the conditioned medium from clone 9\#4 (Fig. 2). Because these two hybridomas were observed as polyclones, we performed monoclonalization of hybridomas by limiting dilution to seed one cell per well in a 96-well cell culture plate, 48 wells for each clone. After the new clones reached confluence, next round ELISA was carried out to screen the positive monoclones. As the results, we obtained several candidate clones 5B5, 5C3, 5D3, 5F4 and 5H5 derived from clone 5\#21 and renamed as 5.1, 5.2, 5.3, 5.4 and also candidate clones 9A7, 9A8, 9D8, 9D11, 9G7, 9G10 and 9H8 derived from clone $9 \# 4$ and renamed as 9.1, 9.2, 9.3, 9.4, 9.5, 9.6, 9.7 (Fig. 3).

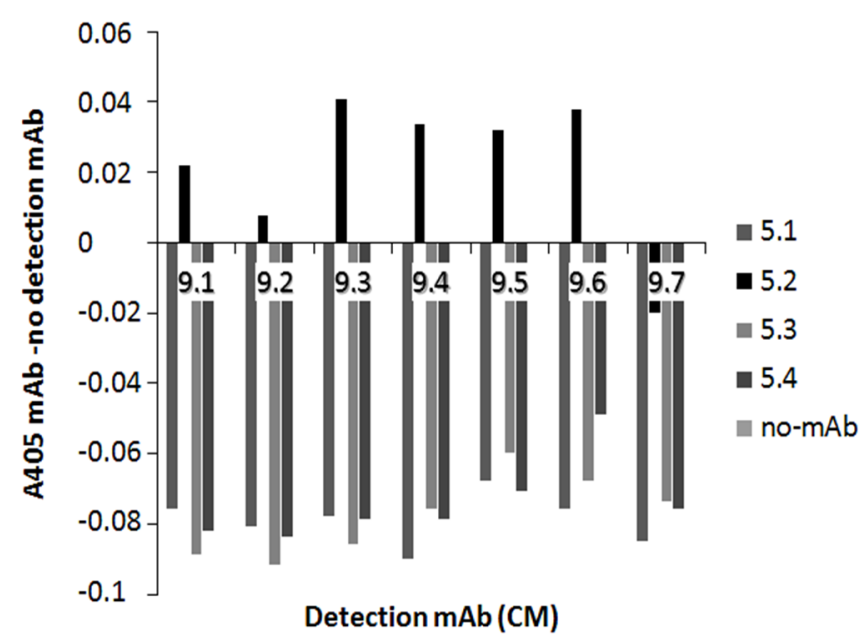

Fig. 4 Screening of candidate anti-HBcAg monoclonal antibodies in conditioned medium for sandwich ELISA.

To establish homemade sandwich ELISA, we selected the candidate monoclonal antibodies by applying them as both capture and detection antibodies. The sandwich consists of candidate capturing antibodies, recombinant $\mathrm{HBcAg}$ peptides, candidate detection antibodies, and HRP-conjugated anti-mouse IgG $\gamma$-chain secondary antibody. The antibodies in wells that produce higher signals than control well without detection antibodies were selected as candidate antibodies. As the results, the wells coated with clone 5.2 conditioned medium representing capture antibody and used clone 9.1, $9.3,9.4,9.5$ or 9.6 conditioned media representing detection antibodies showed higher signals of $\mathrm{HBcAg}$ detection than the control without detection antibodies (Fig. 4). Next, we retrieved clones 9.3, 9.4, and 9.5 conditioned media for antibody purification and further sandwich ELISA after conjugation with HRP.

\section{B. Antibody Purification}

We purified the antibodies by using protein $\mathrm{A} / \mathrm{G}$ agarose to purify general $\mathrm{IgG}$ based antibodies. All candidate $\mathrm{mAb}$ from clones $9.3,9.4$, and 9.5 conditioned media were purified using this method. As we can see in figure 5, the mAbs were successfully purified from serum-free conditioned medium and mostly concentrated in eluate fraction 2. Determination of mAbs concentration by nanodrop results in mAbs concentration 214, 100, and $164 \mathrm{ng} / \mu \mathrm{l}$ for $9.3,9.4$, and 9.5 mAbs, respectively, which represent in the SDS-PAGE gel after coomassie blue staining. The purified antibodies were concentrated in elution fraction 2, which appeared as denatured heavy and light chains (Fig. 5). Purified antibodies were then conjugated with HRP for the development of homemade sandwich ELISA. Unfortunately, the conditioned medium of clone 5.2 was not purified by protein $\mathrm{A} / \mathrm{G}$ agarose, which indicates that $\mathrm{mAb}$ secreted by this clone may not be $\mathrm{IgG}$. We retrieved IgG-based antibodies derived from clone 9\#4 for sandwich ELISA for a further experiment.

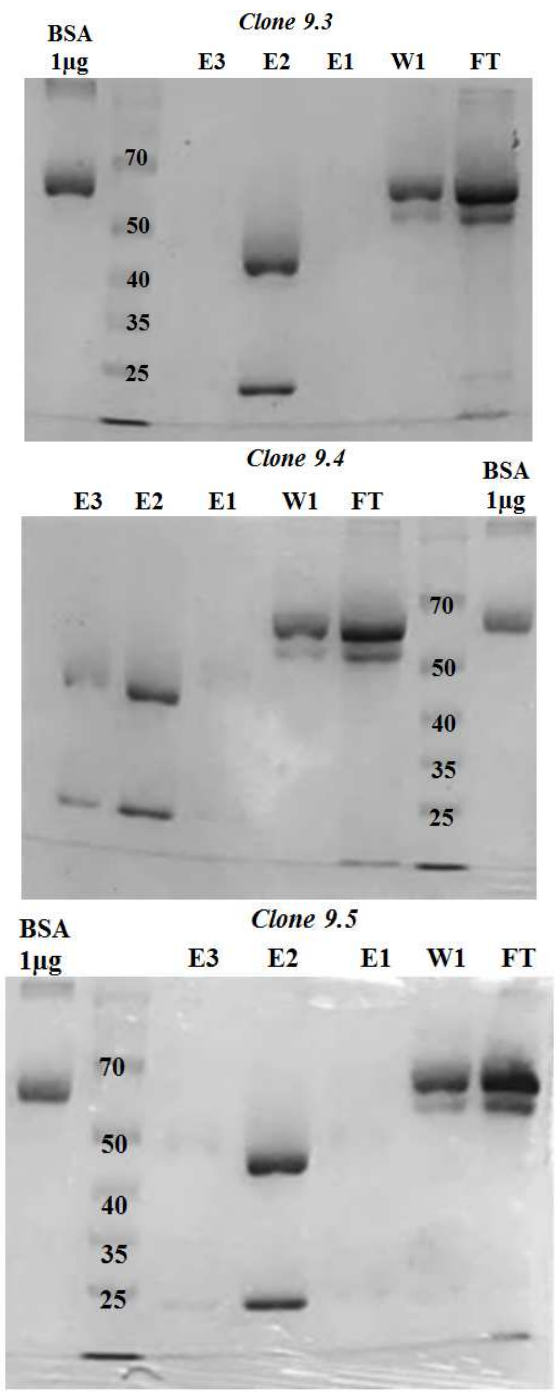

Fig. 5 Profile of anti-HBcAg monoclonal antibodies 9.3, 9.4 and 9.5 in reducing sample buffer after purification by protein $\mathrm{A} / \mathrm{G}$ sepharose. The antibodies appeared as denatured heavy chains and light chains. E: eluate, W: wash, FT: flow through. 

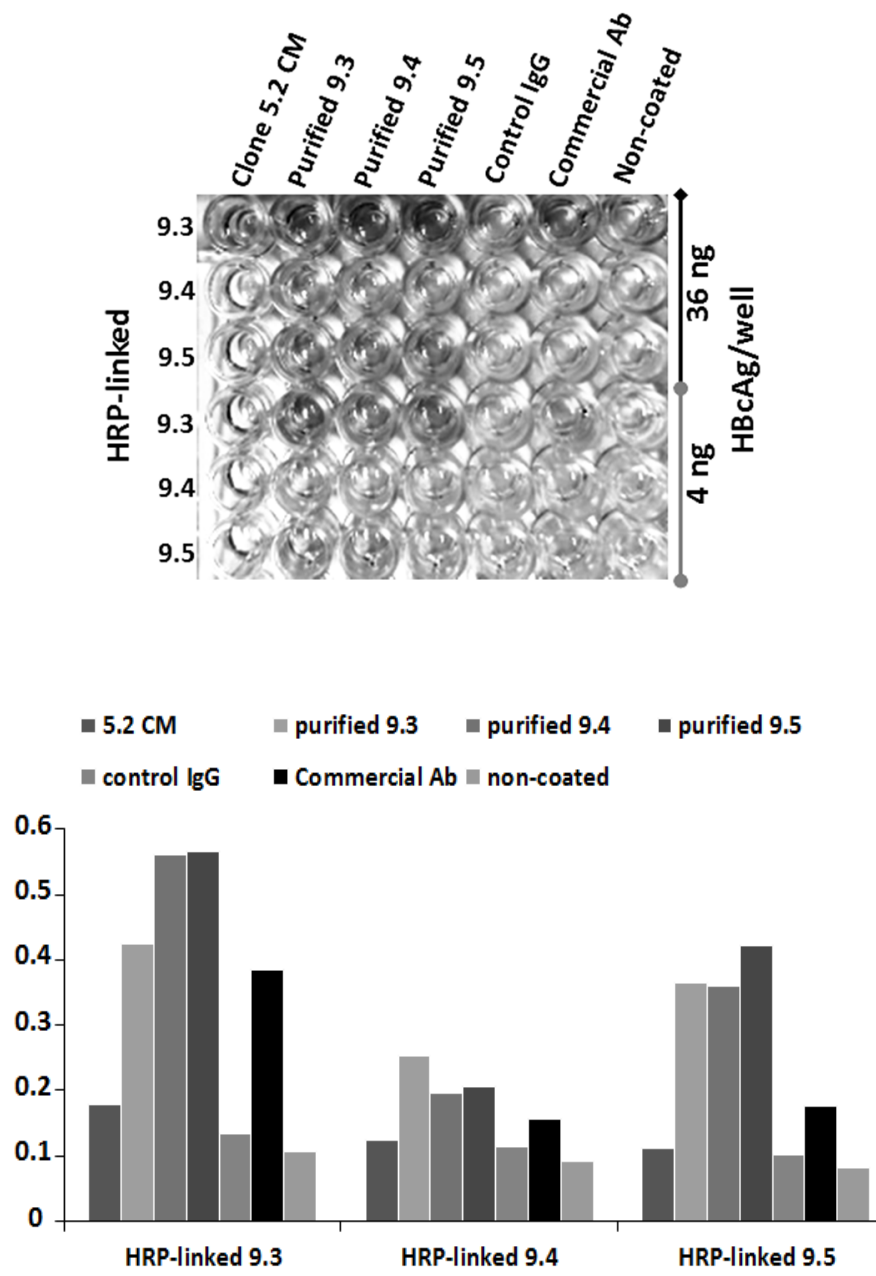

- 5.2 CM $\quad$ purified $9.3 \quad \square$ purified $9.4 \quad \square$ purified 9.5

a control lgG $\quad$ Commercial Ab $\|$ non-coated

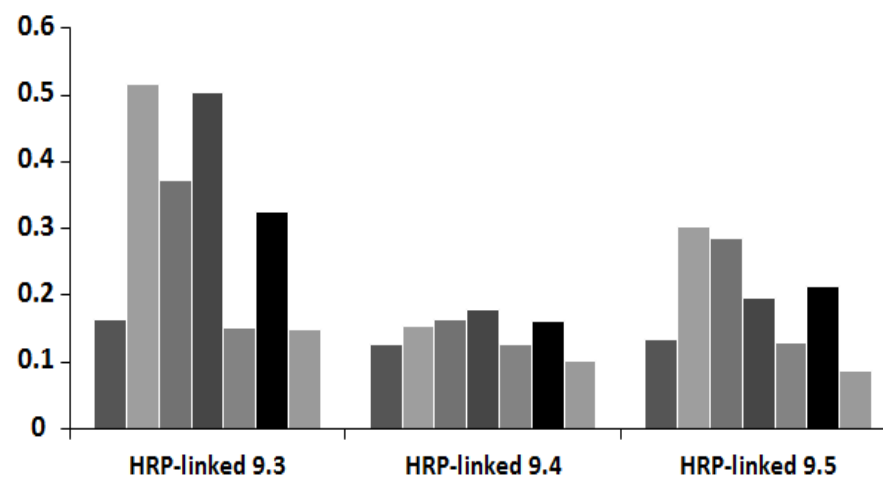

Fig. 6 Application of HRP-linked anti-HBcAg monoclonal antibodies 9.3, 9.4 and 9.5 for sandwich ELISA. Upper Fig., Color development after addition of HRP-linked $\mathrm{mAb}$ and ABTS substrate during sandwich ELISA application utilizing homemade mAbs. Middle and Lower Fig., Absorbance measurement at OD $405 \mathrm{~nm}$. Middle Fig., Sandwich ELISA utilizing $36 \mathrm{ng}$ HBcAg each well. Lower Fig., Sandwich ELISA utilizing 4 ng HBcAg each well.

\section{Establishment of Home-Made Sandwich ELISA}

All antibodies 9.3, 9.4 and 9.5 can be used in ELISA during the screening of mAbs for recombinant HBcAg detection. Furthermore, for sandwich ELISA application, we conjugated those antibodies with HRP to establish easy and fast ELISA consist of several steps: coating of ELISA plate with purified mAbs, blocking with skim milk/PBS-T, the addition of antigen, the addition of HRP-linked mAbs, the addition of ABTS substrate with additional PBS washing before each step. As a result, HRP-linked monoclonal antibody 9.3 showed the highest signal as detection antibody with 9.4 and $9.5 \mathrm{mAbs}$ as capture antibodies (Fig. 6). In addition, the commercial $\mathrm{HBcAg}$ antibody showed a positive signal as our candidates mAbs, while on the contrary, control IgG as capture antibody did not generate a significant signal.

Sandwich ELISA is an easy immunoassay-based method for high-throughput applications. By obtaining monoclonal antibodies, which function as either capture or detection antibodies, the antigen-containing samples can be sandwiched between those antibodies. Detection antibodies can be conjugated to HRP enzyme for further direct color development after chromogenic substrate addition. Here, we successfully retrieved hybridoma clones that produced antiHBcAg mAbs 9.3, 9.4, and 9.5 for sandwich ELISA application. However, further studies are needed to examine the serological samples in comparison to available commercial kits.

Immunostaining of the liver tissue section is another general method to measure chronic hepatitis B patients [41]. The presence of $\mathrm{HBcAg}$ in nuclear hepatocytes indicates an active viral replication. Moreover, $\mathrm{HBcAg}$ also is detected in the cytoplasm representing the current regenerative activity of $\mathrm{HBcAg}$ protein expression and the viral assembly [42]. To expand the research applications of our anti-HBcAg monoclonal antibodies, we will further investigate the capability of those antibodies for immunostaining of tissue section or in vitro cell culture expressing ectopic $\mathrm{HBcAg}$.

\section{CONCLUSION}

We successfully isolated monoclonal hybridomas capable of producing anti-HBcAg monoclonal antibodies for sandwich ELISA application. Those monoclonal antibodies produced by clones $9.3,9.4$, and 9.5 are IgG based antibodies that can be purified using protein $\mathrm{A} / \mathrm{G}$ agarose and conjugated with HRP for easy detection with a chromogenic substrate. HRP-linked monoclonal antibody 9.3 had the highest signal of $\mathrm{HBcAg}$ detection for detection antibody with 9.4 and 9.5 monoclonal antibodies as capture antibodies.

\section{ACKNOWLEDGMENT}

This work was supported by the Indonesia Institute of Sciences (LIPI) DIPA PN 2019 and PN 2021, and Kemenristek/BRIN/LPDP grant No. 91/E1/PRN/2020.

\section{CONFLICT OF INTEREST}

The authors declare that there was no conflict of interest related to this research.

\section{AUTHOR CONTRIBUTIONS}

Conceptualization and methodologies by EPS. Research investigation by EPS, NH, AK, PWP, AP. Funding acquisition by AZM, EPS, and AS. Project administration and ethical clearance document by NH. Writing original draft by 
EPS. Review and editing by AS, PWP, NH, AZM. All authors read and approved the final manuscript.

\section{REFERENCES}

[1] J. Torresi et al., "HBV-related hepatocarcinogenesis: the role of signalling pathways and innovative ex vivo research models," pp. 1$14,2019$.

[2] G. Uptake et al., "Technical bulletin," pp. 4-7.

[3] G. Uptake et al., "Technical bulletin," pp. 1-3.

[4] C. Stasi et al., "Clinical epidemiology of chronic viral hepatitis B : A Tuscany real-word large-scale cohort study," vol. 10, no. 5, pp. 409416, 2018, doi: 10.4254/wjh.v10.i5.409.

[5] Z. Chen, G. Diaz, T. Pollicino, H. Zhao, R. E. Engle, and P. Schuck, "Role of humoral immunity against hepatitis B virus core antigen in the pathogenesis of acute liver failure," vol. 115, no. 48, 2018, doi: 10.1073/pnas.1809028115.

[6] Y. Chen and Z. Tian, "HBV-Induced Immune Imbalance in the Development of HCC," vol. 10, no. August, pp. 1-11, 2019, doi: 10.3389/fimmu.2019.02048.

[7] M. Furuta, H. Tanaka, Y. Shiraishi, and T. Unida, "Characterization of HBV integration patterns and timing in liver cancer and HBV-infected livers," vol. 9, no. 38, pp. 25075-25088, 2018

[8] S. Madihi, H. Syed, F. Lazar, A. Zyad, and A. Benani, "Review Article A Systematic Review of the Current Hepatitis B Viral Infection and Hepatocellular Carcinoma Situation in Mediterranean Countries," vol. $2020,2020$.

[9] L. Fitria and H. Gunardi, "Paediatrica Indonesiana," vol. 50, no. 6, pp. 321-325, 2010

[10] D. H. Muljono, "Epidemiology of Hepatitis B and C in Republic of Indonesia," vol. 7, no. June, pp. 55-59, 2017.

[11] L. Mak and M. Yuen, "Hepatitis B core-related antigen ( HBcrAg): an emerging marker for chronic hepatitis B virus infection," no. April, 2017, doi: 10.1111/apt.14376.

[12] H. B. Virus, "crossm," vol. 33, no. 2, pp. 1-38, 2020.

[13] S. Das, K. Ramakrishnan, S. K. Behera, M. Ganesapandian, A. S. Xavier, and S. Selvarajan, "Review Article Hepatitis B Vaccine and Immunoglobulin: Key Concepts," vol. 7, pp. 165-171, 2019, doi: 10.14218/JCTH.2018.00037.

[14] A. Amini et al., "Diagnostic accuracy of tests to detect hepatitis B surface antigen: a systematic review of the literature and metaanalysis," vol. 17, no. Suppl 1, 2017, doi: 10.1186/s12879-017-2772-

[15] N. C. Siregar, S. I. Ie, and D. H. Muljono, "Occult hepatitis B in blood donors in Indonesia: altered antigenicity of the hepatitis B virus surface protein," pp. 608-614, 2010, doi: 10.1007/s12072-010-92035

[16] W. J. Gastroenterol, "World Journal of," vol. 9327, no. 31, 2018.

[17] T. Wang et al., "Analysis of clinical characteristics and $\mathrm{S}$ gene sequences in chronic asymptomatic HBV carriers with low-level HBsAg," Clin. Res. Hepatol. Gastroenterol., pp. 1-11, 2018, doi: 10.1016/j.clinre.2018.08.015

[18] K. Jackson, B. A. Sci, S. Locarnini, and D. Ph, "Diagnostics of Hepatitis B Virus: Standard of Care and Investigational," vol. 12, no. 1, pp. 5-11, 2018, doi: 10.1002/cld.729.

[19] L. Mak, W. Seto, J. Fung, and M. Yuen, "New Biomarkers of Chronic Hepatitis B," vol. 13, no. 6, pp. 589-595, 2019.

[20] C. A. Level and N. Histor, "Characteristics of Hepatitis B Core Antibody Level in the Natural History of Chronic Hepatitis B - Jian Wang," pp. 1-7, 2020.

[21] A. Urabe, M. Imamura, M. Tsuge, and H. Kan, "The relationship between HBcrAg and HBV reinfection in HBV related post-liver transplantation patients," J. Gastroenterol., vol. 52, no. 3, pp. 366375, 2017, doi: 10.1007/s00535-016-1240-y.

[22] A. Basi, A. Gryciuk, and P. Boci, "Parenteral - Oral Immunization with Plant-Derived $\mathrm{HBcAg}$ as a Potential Therapeutic Vaccine against Chronic Hepatitis B," pp. 1-11, 2019.

[23] X. Cheng, Y. Xia, K. Chayama, B. Rehermann, and T. J. Liang,
"Hepatitis B virus evades innate immunity of hepatocytes but activates macrophages during infection," doi: 10.1002/hep.

[24] J. Fung, Q. M. Hospital, Q. M. Hospital, K. City, and H. Kong, "Linearized hepatitis B surface antigen and hepatitis B core-related antigen in the natural history of chronic hepatitis B," pp. 1-8, 2014.

[25] A. Rokuhara et al., "Clinical evaluation of a new enzyme immunoassay for hepatitis B virus core-related antigen; a marker distinct from viral DNA for monitoring lamivudine treatment," pp. 324-330, 2003

[26] T. Inoue and Y. Tanaka, "The Role of Hepatitis B Core-Related Antigen," 2019

[27] Y. Sado, S. Inoue, Y. Tomono, and H. Omori, "Lymphocytes from Enlarged Iliac Lymph Nodes as Fusion Partners for the Production of Monoclonal Antibodies after a Single Tail Base Immunization Attempt," vol. 39, no. 3, pp. 89-94, 2006, doi: 10.1267/ahc.06001.

[28] G. F. Salih and K. M. Ali, "Identification of hepatitis B virus by polymerase chain reaction technique: performance study and comparison with enzyme-linked immunosorbent assay," 2015.

[29] A. T. Perestam, K. K. Fujisaki, O. Nava, and R. S. Hellberg, "Comparison of real-time PCR and ELISA-based methods for the detection of beef and pork in processed meat products," Food Control, 2016, doi: 10.1016/j.foodcont.2016.07.017.

[30] A. K. Tiwari et al., "Head-to-head comparison of Enzyme Linked Immunosorbent Assay ( ELISA ) and Enhanced Chemiluminescence Immunoassay ( ECLIA ) for the detection of Transfusion Transmitted Disease ( TTD ) Markers; HIV , HCV and HBV in blood donors, in India," J. Virol. Methods, vol. 285, no. August, p. 113962, 2020, doi: 10.1016/j.jviromet.2020.113962.

[31] U. Ghoshal, V. Jain, A. Dey, and P. Ranjan, "Evaluation of enzyme linked immunosorbent assay for stool antigen detection for the diagnosis of cryptosporidiosis among HIV negative immunocompromised patients in a tertiary care hospital of northern India," J. Infect. Public Health, pp. 4-8, 2017, doi: 10.1016/j.jiph.2017.06.007.

[32] Y. Qin and R. S. Y. F. Y. Huang, "Comparison of double antigen sandwich and indirect enzyme- linked immunosorbent assay for the diagnosis of hepatitis C virus antibodies," no. June, pp. 2-7, 2020, doi: 10.1002/jcla.23481.

[33] C. Report, "False-Negative Hepatitis B Virus ( HBV ) Surface Antigen in a Vaccinated Dialysis Patient with a High Level of HBV DNA in the United States," pp. 820-822, 2012, doi: 10.1128/CVI.05696-11.

[34] Q. Yuan et al., "A novel immunoassay for PreS1 and / or core-related antigens for detection of HBsAg variants," J. Virol. Methods, vol. 168 , no. 1-2, pp. 108-113, 2010, doi: 10.1016/j.jviromet.2010.04.029.

[35] G. J. Van Halewijn et al., "Diagnostic and analytical performance of the hepatitis B core related antigen immunoassay in hepatitis B patients," J. Clin. Virol., vol. 114, no. February 2019, pp. 1-5, 2020, doi: 10.1016/j.jcv.2019.03.003

[36] E. K. G. Trindade and R. F. Dutra, "PT SC," Colloids Surfaces B Biointerfaces, 2018, doi: 10.1016/j.colsurfb.2018.08.050.

[37] Y. Kishiro, M. Kagawa, I. Naito, and Y. Sado, "A Novel Method of Preparing Rat-Monoclonal Antibody-Producing by Using Rat Medial Iliac Lymph Node Cells Hybridomas," vol. 156, pp. 151-156, 1995.

[38] H. F. Stills, "Adjuvants and Antibody Production: Dispelling the Myths Associated with Freund's Complete and Other Adjuvants."

[39] V. S. A. Fernández-tejada et al., "Modulation of immune responses using adjuvants to facilitate therapeutic vaccination," vol. 296, no. April, pp. 1-22, 2020, doi: 10.1111/imr.12889.

[40] S. Ols et al., "Route of Vaccine Administration Alters Antigen Trafficking but Not Innate or Adaptive Immunity Report Route of Vaccine Administration Alters Antigen Trafficking but Not Innate or Adaptive Immunity," pp. 3964-3971, 2020, doi 10.1016/j.celrep.2020.02.111.

[41] M. Huang, J. Liu, M. Chow, X. Zhou, Z. Han, and Z. He, "Negative $\mathrm{HBcAg}$ in immunohistochemistry assay of liver biopsy is a predictive factor for the treatment of patients with nucleos $(t)$ ide analogue therapy," vol. XX, no. X, pp. 1-9, 2017, doi: 10.1111/jcmm.13444.

[42] M. Rybicka and K. P. Bielawski, "Recent Advances in Understanding, Diagnosing , and Treating Hepatitis B Virus Infection," 2020. 